\title{
Seasonal and maternal effects on acid-base, L-lactate, electrolyte, and hematological status of 205 dairy calves born to eutocic dams
}

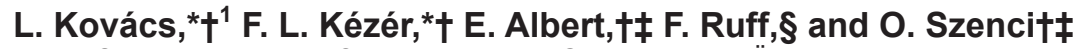 \\ *MTA-SZIE Large Animal Clinical Research Group, H-2225 Üllő-Dóra Major, Hungary \\ †Institute of Animal Husbandry, Faculty of Agricultural and Environmental Science, Szent István University, Páter Károly utca 1, \\ H-2100 Gödöllö, Hungary \\ ‡Department and Clinic for Production Animals, University of Veterinary Medicine, H-2225 Üllö-Dóra Major, Hungary \\ §Department of Methodology, Hungarian Central Statistical Office, Keleti Károly utca 5-7, H-1024, Budapest, Hungary
}

\begin{abstract}
In this study, we used linear mixed models to determine the effects of season, time of sampling relative to birth (factors), duration of the delivery process, duration of maternal grooming, calf body weight (BW) at birth, and time of day (covariates) on values of venous blood gas, acid-base and electrolyte parameters, and L-lactate concentrations in dairy calves born to eutocic dams in summer (SUM, $\mathrm{n}=101)$ and winter (WIN, $\mathrm{n}$ $=104)$. Neonatal vitality was assessed at 0,1 , and 24 $\mathrm{h}$ after delivery in a linear scoring system using muscle tone, erection of the head, muscle reflexes, heart rate, and sucking drive as criteria. Simultaneously with vitality scoring, venous blood samples were collected by jugular venipuncture. Blood was tested for $\mathrm{pH}$, partial pressure of $\mathrm{CO}_{2}\left(\mathrm{pCO}_{2} ; \mathrm{mmHg}\right)$ and oxygen $\left(\mathrm{pO}_{2} ; \mathrm{mmHg}\right)$, L-lactate $(\mathrm{mmol} / \mathrm{L})$, hemoglobin $(\mathrm{Hb}$; $\mathrm{g} / \mathrm{L})$, ionized calcium $\left(\mathrm{Ca}^{2+} ; \mathrm{mmol} / \mathrm{L}\right)$, sodium $\left(\mathrm{Na}^{+}\right.$; mmol/L), potassium $\left(\mathrm{K}^{+} ; \mathrm{mmol} / \mathrm{L}\right)$ and chloride $\left(\mathrm{Cl}^{-}\right.$; $\mathrm{mmol} / \mathrm{L})$. Bicarbonate $\left(\mathrm{HCO}_{3}{ }^{-} ; \mathrm{mmol} / \mathrm{L}\right)$, base excess $(\mathrm{BE} ; \mathrm{mmol} / \mathrm{L})$, total carbon dioxide $\left(\mathrm{TCO}_{2} ; \mathrm{mmol} / \mathrm{L}\right)$, and anion gap $(\mathrm{mmol} / \mathrm{L})$ were calculated. Electrolyte parameters were affected by none of the factors or covariates. Time of day at birth did not affect any of the parameters of interest. Vitality score tended to increase over time and it showed higher values in WIN calves than in SUM calves. Concentrations of $\mathrm{HCO}_{3}^{-}, \mathrm{BE}$, and L-lactate indicated a higher degree of metabolic acidosis in SUM calves; however, $\mathrm{pH}$ was not affected by season. Concentrations of $\mathrm{Hb}$ were higher in SUM calves than in WIN calves; however, covariates did not affect $\mathrm{Hb}$ concentrations. Blood $\mathrm{pH}$, concentrations of $\mathrm{pO}_{2}, \mathrm{HCO}_{3}^{-}$, and $\mathrm{BE}$ decreased, whereas L-lactate concentrations and values of $\mathrm{pCO}_{2}, \mathrm{TCO}_{2}$, and anion gap increased with longer duration of delivery. A shift in acid-base balance was also linked to BW of the calf at
\end{abstract}

Received January 1, 2017

Accepted May 12, 2017.

${ }^{1}$ Corresponding author: Kovacs.Levente@mkk.szie.hu birth, with lower values of blood $\mathrm{pH}, \mathrm{HCO}_{3}^{-}$, and $\mathrm{BE}$ in calves with higher BW compared with those with lower $\mathrm{BW}$ at birth, whereas $\mathrm{TCO}_{2}$ and L-lactate concentrations increased with higher calf BW at birth. Values of $\mathrm{pO}_{2}$ increased and $\mathrm{pCO}_{2}$ decreased with longer duration of maternal grooming. Blood $\mathrm{pH}, \mathrm{HCO}_{3}^{-}$, and $\mathrm{BE}$ increased, whereas L-lactate concentrations and anion gap decreased with longer duration of licking the calf. Our results indicate that prolonged delivery can impair acid-base status and can cause slight lactic acidosis, even in calves born from spontaneous or eutocic calvings, and that high BW at birth predisposes calves to acidosis. The positive effect of maternal grooming on neonatal acid-base status should be considered in parturition management. Season, duration of the delivery process, calf BW at birth, and duration of maternal grooming are recommended for consideration in future studies on blood gas and acid-base parameters in dairy calves in the immediate neonatal period.

Key words: vitality, acid-base balance, season, duration of calving, maternal grooming

\section{INTRODUCTION}

The physiological adaptation of newborn calves to extrauterine life has great importance in terms of neonatal vitality because of the great number of rapid physiological changes during the transition from fetal to neonatal life. In large dairy units, the lack of vitality may go unnoticed, resulting in short- or long-term implications for the health and performance of young animals. About half of all perinatal losses occur during the first $2 \mathrm{~d}$ of life (Vermorel et al., 1983; Schuijt, 1990); therefore, extensive research has explored neonatal calf vitality and several blood parameters related to various obstetrical conditions (Szenci, 2003).

Detailed research on the acid-base status of newborn calves was started in 1977, and studies of this type have been initiated in an increasing number of countries (Szenci, 2003). So far, it has been demonstrated that difficult (Szenci et al., 1988; Lombard et al., 2007) and 
prolonged deliveries (Herfen and Bostedt, 1999) are related to the disturbance of acid-base parameters in newborn calves. Murray et al. (2015) showed that dystocia could also impair the efficiency of IgG absorption and weight gain. However, the definition of dystocia is subject to varying interpretations, which can cause difficulties in field data collection and in the comparison of different studies. The effect of forced extraction on the acid-base balance of newborn calves was presented in the early 1980s (Szenci, 1983). Recent works have shown that mild or severe obstetric assistance affects the adaptation of calves to extrauterine life, especially through compromising the acid-base balance and electrolyte homeostasis of newborn calves (Bleul and Götz, 2013; Vannucchi et al., 2015).

As alternatives for expensive and inconvenient laboratory-intensive, blood-based measurements, several vitality measures based on clinical observations have been developed (Lorenz et al., 2011). These scoring systems are commonly based on the original Apgar scores (e.g., Mülling, 1977) or on the direct observation of lying, walking, or sucking behaviors (Barrier et al., 2012). Other researchers have introduced more practical systems for field conditions (Szenci, 1982; Schuijt and Taverne, 1994). However, it is still debatable whether vitality scores accurately reflect the acid-base status and the proper vitality of the offspring (Murray and Leslie, 2013). In a recent study, Homerosky et al. (2017) showed that traditional Apgar parameters such as heart rate, respiratory rate, and mucous membrane color are not useful for the identification of calves with acidemia. Another problem with the assessment of assistancerelated differences in clinical parameters is that the results may have been confounded by decisions made by the stockperson as to when assistance was necessary. The majority of long-standing studies on neonatal vitality have focused on the physiological concerns of difficult calvings; however, severe and life-threatening acidosis (Bleul et al., 2008) and hypoxia (Bleul, 2009) can occur even after spontaneous deliveries.

Therefore, the objective of the present study was to characterize the acid-base and electrolyte status of newborn calves born to eutocic dams. The respira- tory and metabolic components of acidosis (short-term well-being) as well as parameters suitable for assessing potential life-threatening neonatal asphyxia by reflecting long-term changes in blood gas exchange were investigated. We attempted to identify seasonal, maternal, and calf-related variables that have not previously been considered and might have potential effects on blood parameters of primary acid-base disturbances in the first $24 \mathrm{~h}$ of life of bovine neonates. We presumed impaired vitality, acid-base status, and higher L-lactate concentrations in calves born in summer than those born in winter.

\section{MATERIALS AND METHODS}

\section{Experimental Design}

The experiment was carried out on a large-scale dairy farm in Hungary with around 900 lactating HolsteinFriesian cows. Two hundred and five neonatal calves born in summer [SUM, $\mathrm{n}=101$; between June 15 and August 20, 2013; average temperature (range) $=24.6^{\circ} \mathrm{C}$ $\left(14.7-38.7^{\circ} \mathrm{C}\right)$ ] and winter [WIN, $\mathrm{n}=104$; between November 25, 2013, and February 15, 2014; average temperature (range) $\left.=4.3^{\circ} \mathrm{C}\left(1.7-11.2^{\circ} \mathrm{C}\right)\right]$ from eutocic calvings were included in the study.

Eutocic calving was considered as a combination of "no assistance" and "slight assistance" (where assistance or traction was brief and slight, and the cow may otherwise have calved unassisted) by one person (Mee et al., 2011). The BCS of the dam was scored using the 5-point scoring system (Hady et al., 1994) immediately after calving. Assistance rates and other characteristics of calvings are presented in Table 1. Calves born from prolonged spontaneous calvings ( $>2 \mathrm{~h}$ from appearance of hooves to delivery) and calvings needing assistance by 2 or more people with considerable force (using obstetrical ropes) or using a calf jack during delivery were considered dystocic and were excluded from the investigation.

Preparturient heifers and cows were housed in a barn bedded with straw $28 \mathrm{~d}$ before the expected date of calving. A TMR was provided ad libitum and water

Table 1. Characteristics of calvings involved in this study (means \pm SD)

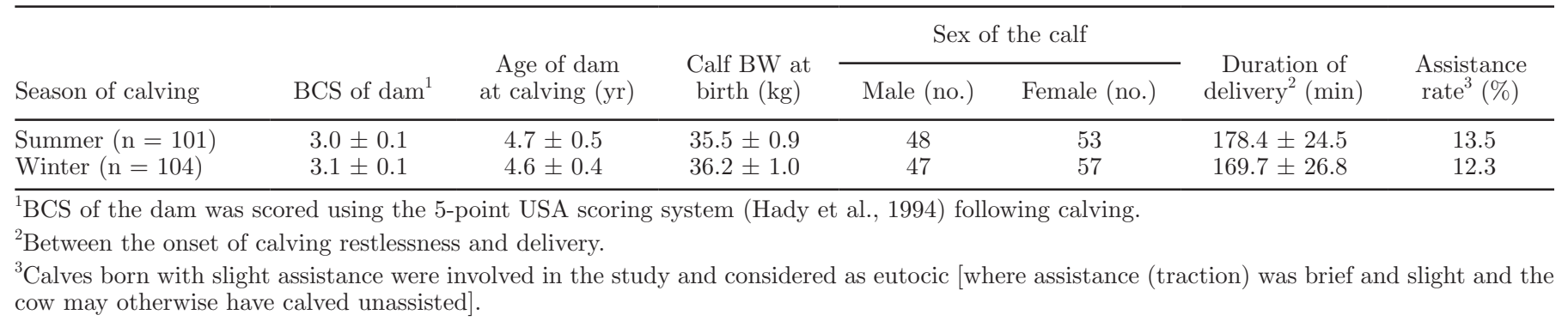


was available at all times. Supervision was routinely ensured once per hour for $24 \mathrm{~h} / \mathrm{d}$ by farm staff. Calvings took place in the group pen or, if continuous supervision or obstetrical assistance was required at calving, in a separated maternity pen. For more details on calving management, see Kovács et al. (2016). Calves were removed from the dams within $1.5 \mathrm{~h}$ after birth. Within $2 \mathrm{~h}$ after calving, the dam was milked, and colostrum was provided to the newborn calves by nipple bottle. Calves were routinely fed 4 times a day with $1.65 \mathrm{~L}$ of fresh-cow colostrum per feeding during the first 48 $\mathrm{h}$ of life. Between 48 and $96 \mathrm{~h}$ after birth, calves were fed 3 times a day. Afterward, calves were offered 3.2 L of whole milk from plastic buckets 2 times a day (at 0500 and $1600 \mathrm{~h}$ ). Newborns were housed individually in $1.65-\times 1.20-\mathrm{m}$ plastic calf hutches with a $1.60-\mathrm{m}^{2}$ exercise pen, both bedded with straw. Straw was provided as needed. Management of calving, neonatal assistance (i.e., respiratory and thermal support, manual feeding of colostrum at the first feeding), and feeding of newborns during the first $24 \mathrm{~h}$ of life did not differ between seasons and was constant during the experimental period. Calves were housed individually in $1.65-\times 1.20-\mathrm{m}$ plastic calf hutches with a $1.60-\mathrm{m}^{2}$ exercise pen, both bedded with straw that was provided as needed.

\section{Vitality Scoring and Acid-Base Analysis}

Neonatal vitality was assessed by the first author immediately after birth, and then 1 and $24 \mathrm{~h}$ after delivery. The criteria recommended by Szenci (1982) were used in a linear scoring system also including sucking drive, as follows: (1) muscle tone $(2=$ normal, $1=$ low, $0=$ toneless); (2) erection of the head $(2=$ erected head, $1=$ head requiring support; $0=$ head dropping); (3) muscle reflexes $(2=$ normal reflectory movements, $1=$ reduced number and intensity of reflectory movements, $0=$ limbs extended); (4) heart rate $(2=$ normal/regular 120-220 beats/min, 1 = bradycardia/irregular $<120$ beats/min, $0=$ absent $)$; (5) sucking drive $(2=$ intensive, $1=$ reduced, $0=$ absent). Following the vitality assessment, scores were summed.

Simultaneously with vitality scoring, venous blood samples were collected by jugular venipuncture when calves were in lateral recumbency for at least $1 \mathrm{~min}$ following posture change, using syringes with $\mathrm{Ca}^{2+}$ balanced lithium heparin preparation (Blood Gas Monovette 2 mL LH, Sarstedt, Nümbrecht-Rommelsdorf, Germany). Rectal temperature was measured at the time of blood samplings. Within 5 min of collection, blood was tested using the ABL800 Basic system (Radiometer Medical ApS, Brønshøj, Denmark). Blood pH, partial pressures of $\mathrm{CO}_{2}\left(\mathbf{p C O}_{2} ; \mathrm{mmHg}\right)$ and oxygen $\left(\mathbf{p O}_{2} ; \mathrm{mmHg}\right)$, and concentrations of L-lactate $(\mathrm{mmol} / \mathrm{L})$, hemoglobin $(\mathrm{Hb}$; $\mathrm{g} / \mathrm{L})$, ionized calcium $\left(\mathrm{Ca}^{2+} ; \mathrm{mmol} / \mathrm{L}\right)$, sodium $\left(\mathrm{Na}^{+} ;\right.$ $\mathrm{mmol} / \mathrm{L})$, potassium $\left(\mathrm{K}^{+} ; \mathrm{mmol} / \mathrm{L}\right)$ and chloride $\left(\mathrm{Cl}^{-}\right.$; $\mathrm{mmol} / \mathrm{L})$ were measured. Concentrations of bicarbonate $\left(\mathrm{HCO}_{3}{ }^{-}, \mathrm{mmol} / \mathrm{L}\right)$ and total carbon dioxide $\left(\mathbf{T} \mathbf{C O}_{2}\right.$; $\mathrm{mmol} / \mathrm{L})$, the base excess $(\mathbf{B E} ; \mathrm{mmol} / \mathrm{L})$, and the anion gap $(\mathrm{mmol} / \mathrm{L})$ were calculated by the analyzer. The anion gap was calculated as follows: Anion gap $=\left[\mathrm{Na}^{+}\right]$ $-\left[\mathrm{Cl}^{-}\right]-\left[\mathrm{HCO}_{3}^{-}\right]$. Blood $\mathrm{pH}, \mathrm{pCO}_{2}, \mathrm{pO}_{2}, \mathrm{TCO}_{2}$, and $\mathrm{BE}$ were corrected for body temperature of the calf.

\section{Characteristics of Calving}

To evaluate the effect of delivery process duration on the examined blood parameters of newborn calves, the time lag between the onset of calving restlessness and delivery was recorded. The onset of calving restlessness was registered based on video recordings (by 2 day/ night outdoor network bullet cameras installed above the group pen; Vivotek IP8331, Vivotek Inc., Taiwan) and established according to generally accepted behavioral predictors (Miedema et al., 2011). The BW and sex of the calf, as well as the time of day at birth, were recorded immediately after birth. Following Jensen (2012), parent-offspring interaction was also recorded, and licking of the calf's head/body was considered when the dam's tongue was in contact with the calf's head or body. The duration of licking the calf was measured for each cow within the first $1 \mathrm{~h}$ after delivery.

\section{Statistics}

Statistical analyses were performed in the $\mathrm{R} 3.0 .2$ statistical environment and language ( $\mathrm{R}$ Core Team, 2013). To evaluate the effects of season and time of sampling relative to birth $(0,1$, and $24 \mathrm{~h}$ min after delivery), the interactions between these factors and the effect of the covariates (BW of the calf at birth, time of day at birth, duration of the delivery process, and time spent licking the calf) on the dependent variables (rectal temperature and blood parameters), data were analyzed with linear mixed-effects models (LMM).

Pseudo-replication was avoided by including the identity of calves as a random factor in the models. All models were calculated with type I sums of squares that consider the order of entry of effects into the model. The covariate "duration of the delivery process" was consistently entered into the model first, and we allowed for an interaction effect of duration of the delivery process and calf identity. After "duration of the delivery process," the "time spent licking the calf" was entered into the model, because effects of season and time spent licking the calf were, to some extent, confounded and the effect of time spent licking the calf on the blood parameters was considered more intui- 
tive. The 2 covariates "duration of the delivery process" and "time spent licking the calf" were included in all reduced models, even when they were not statistically significant. The fixed effect factors season and time of sampling relative to birth, as well as calf BW at birth and the time of day at birth were entered after the duration of maternal grooming (the time spent licking the calf within the first hour after delivery) and left out of reduced models if they did not contribute significantly to the explanation of the dependent variable. The residuals of all models were inspected graphically for distribution and homogeneity of variances. None of the residuals corresponding to data presented here had a statistically significant $(P<0.05)$ deviation from normal distribution based on the Shapiro-Wilk test.

\section{RESULTS AND DISCUSSION}

\section{Effects of Season and Time of Sampling Relative to Birth}

Changes in vitality score, rectal temperature, and venous blood gas and acid-base values according to season and time of sampling relative to birth are presented in Figures 1, 2, and 3. Effect of season and time of sampling relative to birth are shown in Table 2 .

Assessment of vitality immediately after birth revealed that 137 calves were normal (vitality score >7.5), 60 calves exhibited slight depression (vitality score $=5.0-7.5)$, and 8 exhibited severe depression (vitality score $<5.0$ ). In agreement with previous findings (Szenci, 2003) and recent reports (Kovács et al., 2016), vitality score tended to increase over time and, interestingly, it showed higher values in WIN calves than in SUM calves (Figure 1). Although mortality did not occur within the 24-h period of observation, our results seem to be in contrast with the finding of Azzam et al. (1993) that neonatal survival rate was lower at low environmental temperatures. Even though the calculation of vitality scores prevented its accurate involvement in statistical analysis, it seemed that vitality was higher in winter than in summer (Figure 1), which might be associated with respiration aided by a decrease in environmental temperature relative to intrauterine conditions (Maurer-Schweizer et al., 1977; Guyton and Hall, 2006). It is a limitation of our study that respiratory frequency was not measured at the same time as vitality scoring.

In line with literature data (Bellows and Lammoglia, 2000; Vannucchi et al., 2015), rectal temperature showed significant changes over time (Figure 2); however, these changes were irrespective of season (Table 2). All calves exhibited normothermia at birth, and there was a significant decrease in rectal temperature during the first

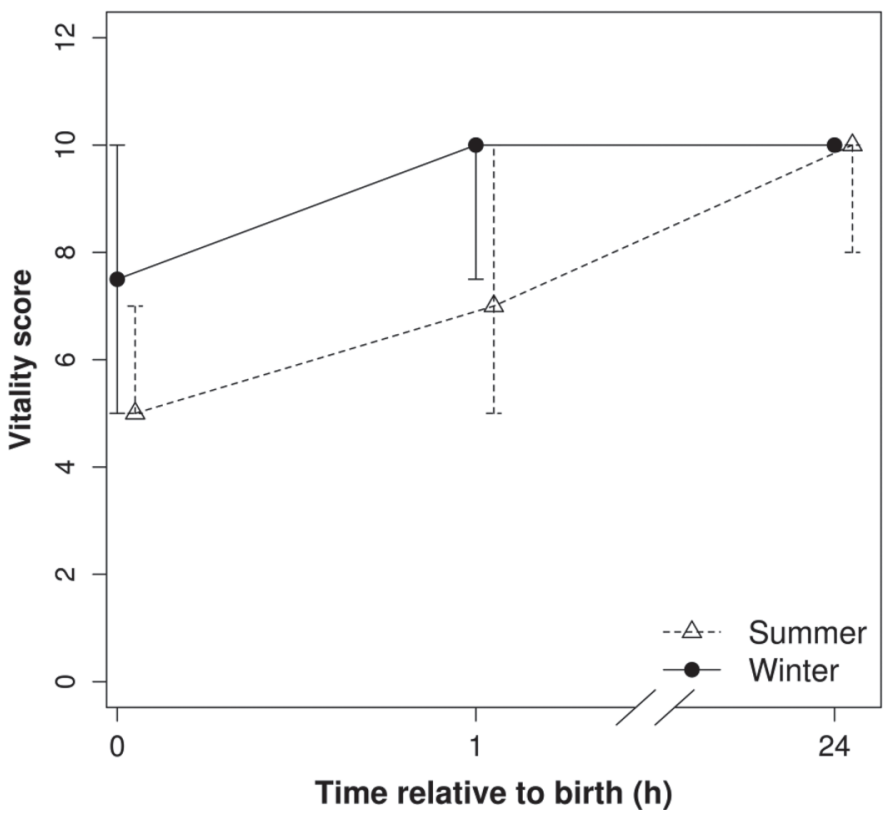

Figure 1. Vitality scores of newborn calves delivered from eutocic calvings at 0,1 , and $24 \mathrm{~h}$ after delivery in summer $(\Delta, \mathrm{n}=101)$ and winter $(\bullet, \mathrm{n}=104)$. Newborn calf vitality was evaluated on a scale from 0 to 10 , using the following 5 criteria: muscle tone, erection of the head, muscle reflexes, heart rate, and sucking drive, with 2 scores for each. Values are presented as median \pm interquartile range. In case of $0 \mathrm{~h}$ summer, quartile $(\mathrm{Q}) 1=$ median; in case of $1 \mathrm{~h}$ winter, Q3 = median; in case of $24 \mathrm{~h}$ winter, $\mathrm{Q} 1=\mathrm{Q} 3=$ median; and in case of 24 h summer, Q3 = median.

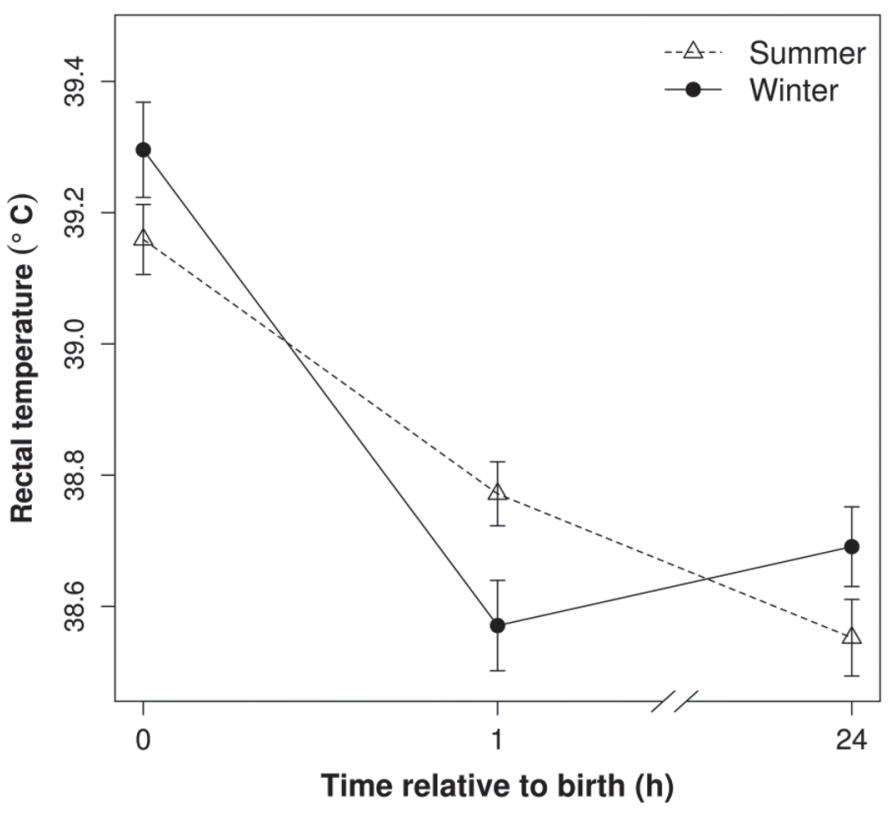

Figure 2. Changes in rectal temperature of newborn calves delivered from eutocic calvings during the first $24 \mathrm{~h}$ of life in summer $(\Delta$ $\mathrm{n}=101)$ and winter $(\bullet, \mathrm{n}=104)$. Values are presented as means \pm SEM. 

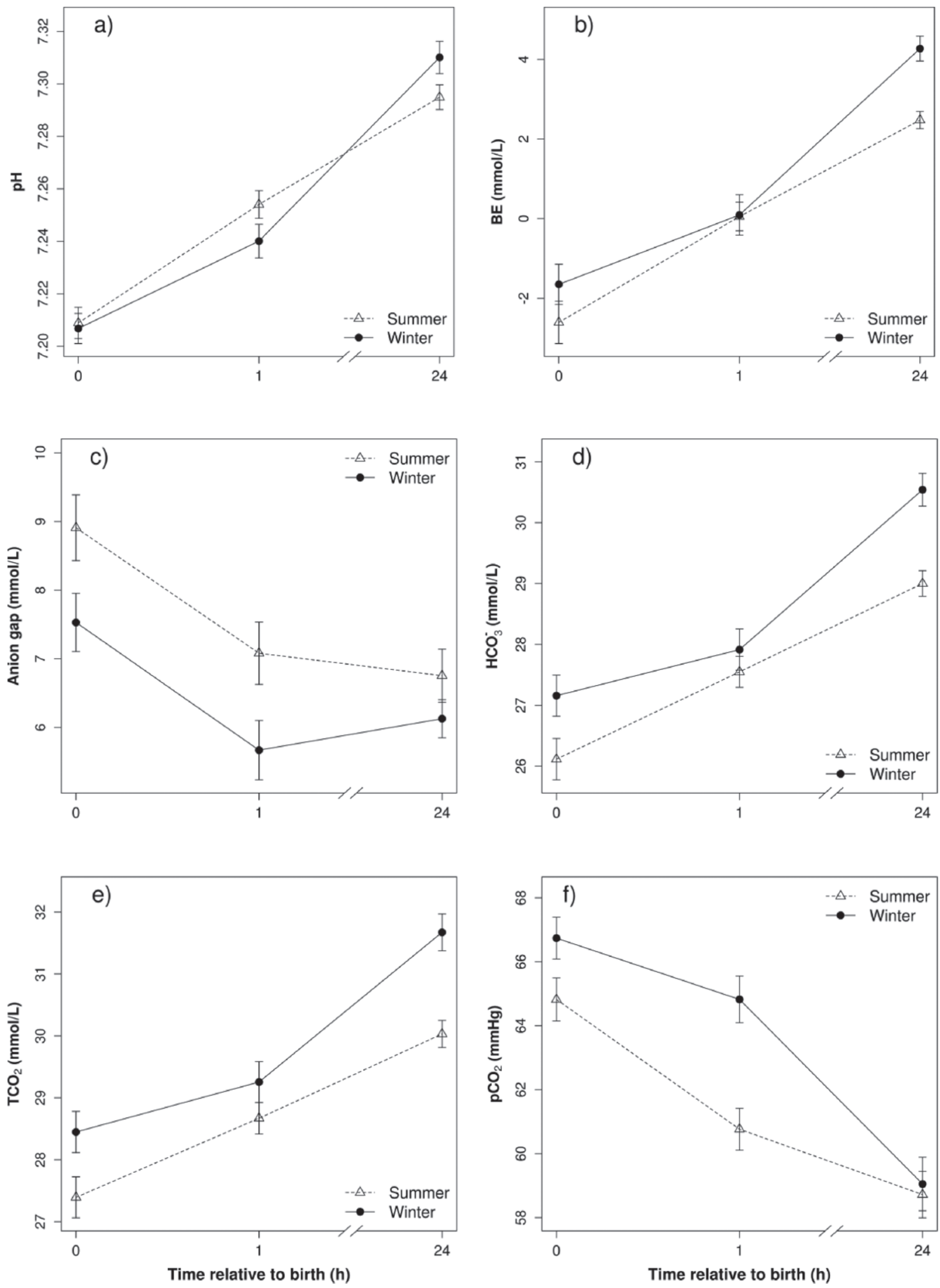

Figure 3. (a) Blood pH, (b) base excess (BE), (c) anion gap, (d) bicarbonate $\left(\mathrm{HCO}_{3}^{-}\right)$, (e) total $\mathrm{CO}_{2}\left(\mathrm{TCO}_{2}\right)$, (f) partial pressure of $\mathrm{CO}_{2}$ $\left(\mathrm{pCO}_{2}\right),(\mathrm{g})$ partial pressure of $\mathrm{O}_{2}\left(\mathrm{pO}_{2}\right),(\mathrm{h})$ L-lactate, and (i) hemoglobin $(\mathrm{Hb})$ of newborn calves delivered from eutocic calvings at 0 , 1 , and $24 \mathrm{~h}$ after calving in summer $(\Delta, \mathrm{n}=101)$ and winter $(\bullet, \mathrm{n}=104)$. Values of $\mathrm{pH}, \mathrm{pCO}_{2}, \mathrm{BE}, \mathrm{TCO}_{2}$, and $\mathrm{pO}_{2}$ are corrected for calf body temperature, and values for all parameters are presented as means \pm SEM. 

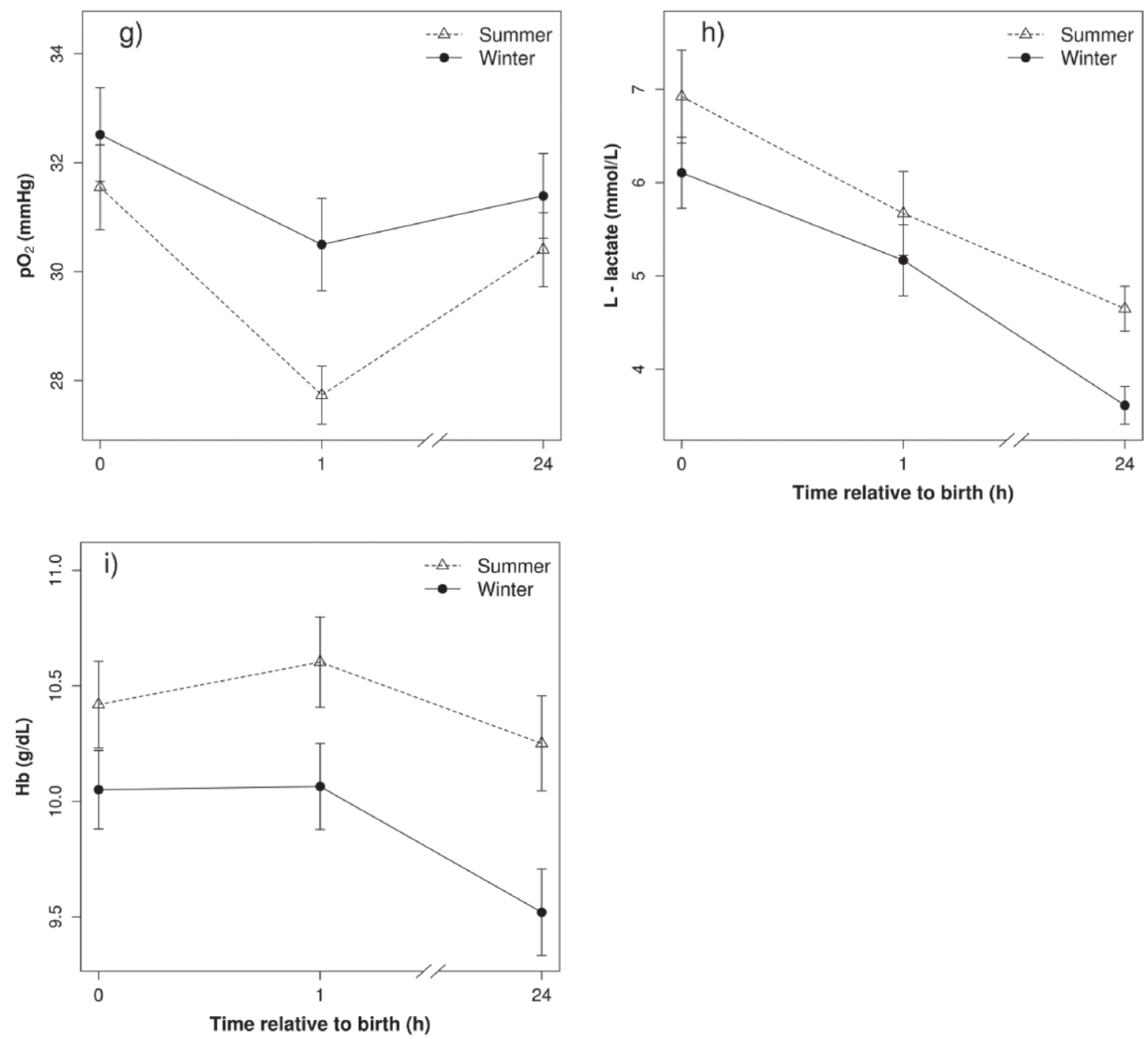

Figure 3 (Continued). (a) Blood pH, (b) base excess (BE), (c) anion gap, (d) bicarbonate $\left(\mathrm{HCO}_{3}^{-}\right)$, (e) total $\mathrm{CO}_{2}\left(\mathrm{TCO}_{2}\right)$, (f) partial pressure of $\mathrm{CO}_{2}\left(\mathrm{pCO}_{2}\right),(\mathrm{g})$ partial pressure of $\mathrm{O}_{2}\left(\mathrm{pO}_{2}\right),(\mathrm{h})$ L-lactate, and (i) hemoglobin $(\mathrm{Hb})$ of newborn calves delivered from eutocic calvings at 0,1 , and $24 \mathrm{~h}$ after calving in summer $(\Delta, \mathrm{n}=101)$ and winter $(\bullet, \mathrm{n}=104)$. Values of $\mathrm{pH}, \mathrm{pCO}_{2}, \mathrm{BE}, \mathrm{TCO}_{2}$, and $\mathrm{pO}_{2}$ are corrected for calf body temperature, and values for all parameters are presented as means \pm SEM.

$1 \mathrm{~h}$ of life in both SUM and WIN calves, with slightly lower values for WIN than for SUM calves, reflecting the impaired neonatal compensatory capacity of thermoregulatory mechanisms in calves under low external temperatures. Higher rectal temperature immediately after birth might reflect increased core temperature of the dam due to labor. In our recent work, we found a significant increase in core temperature of the dam during the last $6 \mathrm{~h}$ before delivery (Kovács et al., 2017).

Although it remained physiological, rectal temperature decreased in the first $24 \mathrm{~h}$ in summer; however, in WIN calves, a slight increase was observed between 1 and $24 \mathrm{~h}$ after delivery (Figure 2). The slightly higher rectal temperatures at $24 \mathrm{~h}$ in winter compared with summer could be associated with increased heat production in WIN calves to maintain homeothermy. Barrier et al. (2013) reported similar results for dystocic calves regardless of the ambient temperature. It thus seems that the thermoregulatory mechanism of newborn calves is effective in preventing hypothermia, even at low ambient temperatures.

No interactions were found between factors (season, time of sampling) and covariates (duration of the delivery process, calf BW at birth, duration of maternal grooming, time of day at birth). Except for the macroelements measured, blood $\mathrm{pH}$, blood gases, acid-base values, and L-lactate and $\mathrm{Hb}$ concentrations showed changes over time (Figure 3), with significant interac- 
tions between season and time of sampling relative to birth for BE and $\mathrm{TCO}_{2}$ as shown by the LMM analysis (Table 2).

Normal parturition generally results in a combined respiratory-metabolic acidosis (Rice, 1994; Bleul et al., 2007) because of physiological ischemia in the fetoplacental unit (Szenci, 2003). In accordance with previous findings on spontaneously delivered calves (Szenci et al., 1988), or calves delivered either from dystocia (Bleul and Götz, 2013), by caesarean section or natural delivery (Herfen and Bostedt, 1999), the values of blood $\mathrm{pH}$ and $\mathrm{BE}$ reflected a slight to moderate metabolic acidosis immediately after birth that, consistent with previous reports (Szenci, 1985; Szenci, 2003; Bleul and Götz, 2013), was compensated for within the first hour after delivery (Figure 3a and b). Interestingly, despite negative BE after delivery (which was still physiological) for both seasons $[\mathrm{BE}=-2.3 \pm 0.2 \mathrm{mmol} / \mathrm{L}(\mathrm{SUM})$; $\mathrm{BE}=-2.0 \pm 0.1 \mathrm{mmol} / \mathrm{L}(\mathrm{WIN})]$, the values of anion gap (Figure 3c) were within the physiological range at birth [anion gap $=8.9 \pm 0.6 \mathrm{mmol} / \mathrm{L}(\mathrm{SUM})$; anion gap $=7.5 \pm 0.5 \mathrm{mmol} / \mathrm{L}(\mathrm{WIN})]$. This reflects the so-called normal anion gap metabolic acidosis (or hyperchloremic acidosis) characterized by the loss of $\mathrm{HCO}_{3}{ }^{-}$ions accompanied by increased $\mathrm{Cl}^{-}$concentration (Constable, 2014), which was observed both for SUM $(105.3 \pm 3.6$ $\mathrm{mmol} / \mathrm{L})$ and WIN calves $(106.1 \pm 3.5 \mathrm{mmol} / \mathrm{L})$ in the present study. It has to be noted that, due to the experimental setting (only eutocic calvings were included), blood gases and acid-base values were not seriously impaired in either SUM or WIN calves and BE values did not reach the critical $-6.0 \mathrm{mmol} / \mathrm{L}$ threshold value established by Held et al. (1985).

The metabolic component of acidosis was clearly shown by higher L-lactate (Figure 3f) and lower $\mathrm{HCO}_{3}{ }^{-}$ and $\mathrm{TCO}_{2}$ concentrations (Figure 3d and e) at birth in the present study. As for blood $\mathrm{pH}$ and $\mathrm{BE}$, a significant increase was observed for $\mathrm{HCO}_{3}^{-}$and $\mathrm{TCO}_{2}$ concentrations over the first $24 \mathrm{~h}$, whereas levels of L-lactate decreased (Figure 3d-f), reflecting the metabolic compensation of acidosis.

All calves were hypercapnic at birth, and $\mathrm{pCO}_{2}$ values decreased over time during the first $24 \mathrm{~h}$ of life (Figure 3f) in accordance with earlier findings (MaurerSchweizer et al., 1977; Varga et al., 2001). The decline in $\mathrm{pCO}_{2}$ concentrations from delivery to 1 and $24 \mathrm{~h}$ after birth represented the development of respiratory functions, supporting the notion that healthy calves are able to self-correct hypercapnia within the first hours of life (Varga et al., 2001). The development of respiratory functions was reflected by $\mathrm{pO}_{2}$ as well (Figure $3 \mathrm{~g}$ ); however, the effect of time of sampling relative to birth was

Table 2. $P$-values for main effects of factors season (summer, $\mathrm{n}=101$; winter, $\mathrm{n}=104)$ and time of sampling relative to birth $(0,1$ and $24 \mathrm{~h}$ after birth), their interactions, and effects of covariates on rectal temperature, venous blood gas and acid-base, and electrolyte status of newborn calves delivered from eutocic calvings ${ }^{1}$

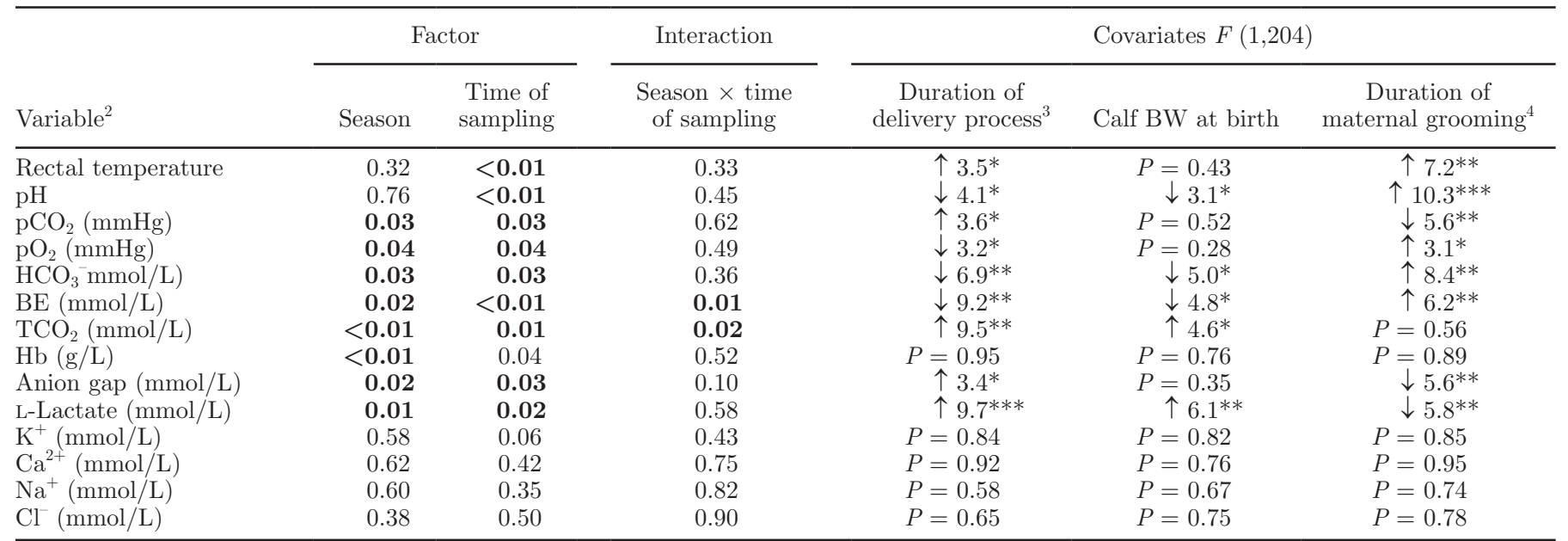

${ }^{1} F$-statistics are based on the ANOVA output for the reduced linear mixed effects models (LMM) based on dependent data. Values in bold indicate significant effect of factors season and time of sampling relative to birth and interactions between the main factors. Arrows indicate variable increases and decreases with increase in covariates. For changes in rectal temperature and blood parameters according to season and time of sampling relative to birth see Figures 1, 2, and 3.

${ }^{2} \mathrm{pCO}_{2}=$ partial pressure of $\mathrm{CO}_{2} ; \mathrm{pO}_{2}=$ partial pressure of oxygen; $\mathrm{HCO}_{3}{ }^{-}=$bicarbonate; $\mathrm{BE}=$ base excess; TCO $2=$ total carbon dioxide; $\mathrm{Hb}$ $=$ hemoglobin.

${ }^{3}$ Between the onset of calving restlessness and delivery.

${ }^{4}$ Duration of licking calf's head or body $(\mathrm{min})$ within the first $1 \mathrm{~h}$ after delivery.

${ }^{*} P<0.05,{ }^{* *} P<0.01,{ }^{* * *} P<0.001$. 
significant only for $\mathrm{pO}_{2}$ (Table 2). As in earlier reports (Kurz and Willett, 1991; Harvey, 1997), the concentration of $\mathrm{Hb}$ was high immediately after delivery (Figure $3 i$ ) however, it did not change significantly over the first $24 \mathrm{~h}$ of life. The slight decrease in $\mathrm{Hb}$ at $24 \mathrm{~h}$ after birth was associated with the plasma volume expansion from colostrum absorption.

One of our main findings could be the effect of season on the concentrations of venous blood gas and acid-base parameters, anion gap, and L-lactate and $\mathrm{Hb}$ concentrations. When the duration of licking the calf within the first hour of life was not taken into account, L-lactate concentrations and blood gas and acid-base parameters differed significantly between SUM and WIN calves. However, as summarized in Table 2, when all the covariates were taken into account, season did not have a significant effect on blood $\mathrm{pH}$ either. Concentrations of $\mathrm{HCO}_{3}^{-}, \mathrm{BE}$, and L-lactate were higher in WIN than in SUM calves (Table 2), with BE values being almost twice as high in winter at $24 \mathrm{~h}$ after birth (Figure 3b) and with $\mathrm{HCO}_{3}^{-}, \mathrm{BE}$, and L-lactate levels reflecting a higher degree of metabolic acidosis in summer. Although $\mathrm{pCO}_{2}$ and $\mathrm{pO}_{2}$ reflected a higher respiratory effectiveness in WIN calves than in SUM calves (Figure 3f and g) with a significant seasonal effect (Table 2), all metabolic and respiratory parameters reached physiological levels in summer for $24 \mathrm{~h}$ after delivery; thus, no serious impairment of blood gas and acid-base balance in SUM calves could be assumed in this study. Because the LMM analysis showed no season $\times$ calf $\mathrm{BW}$ at birth or season $\times$ duration of the delivery process interaction, and values for both covariates were similar for SUM and WIN calves (Table 1), we could not prove a significant effect of calf BW or birth duration on seasonal differences in blood gas, acid-base, or L-lactate values. The reasons for the pronounced seasonal differences in blood gas, acid-base, L-lactate, and $\mathrm{Hb}$ values remain unclear; however, seasonality in these parameters should be considered not only as a clinical concern but also, particularly in long-term experiments, in terms of methodology.

Calves had normal electrolyte parameters during the study period and, in contrast to blood gas and acid-base parameters and $\mathrm{Hb}$ levels, season or time of sampling relative to birth had no effect on the concentrations of $\mathrm{K}^{+}, \mathrm{Ca}^{2+}, \mathrm{Na}^{2+}$, and $\mathrm{Cl}^{-}$(Table 2). Normokalemia $(4.48-5.02 \mathrm{mmol} / \mathrm{L})$, normonatremia (135.3-138.7 $\mathrm{mmol} / \mathrm{L})$, normocalcemia $(1.31-1.39 \mathrm{mmol} / \mathrm{L})$, and normochloridemia $(99.4-104.8 \mathrm{mmol} / \mathrm{L})$ exhibited by the calves in the present study suggested that, in agreement with previous findings (Szenci et al., 1994), newborn calves from eutocic delivery have efficient mechanisms for achieving electrolyte homeostasis.

\section{Effects of Covariates}

No interactions were found between covariates (duration of the delivery process, calf BW at birth, duration of maternal grooming, time of day at birth). Covariates other than time of day at birth had a statistically significant effect on rectal temperature, L-lactate concentration, and on the majority of blood gas and acid-base parameters. None of the covariates affected $\mathrm{Hb}$ concentrations or the parameters of electrolyte homeostasis (Table 2).

The duration of the delivery process (between the first behavioral signs of calving restlessness and birth) affected rectal temperature (Table 2). Calves born from prolonged eutocic deliveries showed higher rectal temperatures than those born from deliveries of shorter duration. All venous blood gas and acid-base parameters and the anion gap were affected by the duration of the delivery process. Blood $\mathrm{pH}$ and concentrations of $\mathrm{pO}_{2}, \mathrm{HCO}_{3}^{-}$, and $\mathrm{BE}$ decreased, whereas the values of $\mathrm{pCO}_{2}, \mathrm{TCO}_{2}$, L-lactate concentration, and anion gap increased with a longer duration of delivery (Table 2), suggesting that prolonged deliveries can impair blood gas and acid-base status and cause hypoxia, even in calves born from spontaneous or eutocic calvings. Bleul and Götz (2013) also observed lower values of venous blood $\mathrm{pH}$ in calves born from prolonged parturitions at 10 min after birth; however, in contrast with our data, duration of delivery had no effect on $\mathrm{pCO}_{2}$ in their study. Because Bleul and Götz (2013) used the time between obstetrically induced rupture of the allantoic sac and birth and only $30 \%$ of the calves were delivered spontaneously in their study, a meaningful comparison of their findings with the present observation is not possible. As the duration of delivery had a highly significant effect on $\mathrm{BE}$ and $\mathrm{TCO}_{2}$ values, our findings seem to support the assumption that the severity of respiratory acidosis depends on the time between the disturbance of maternal blood circulation to the fetus and the onset of successful respiration (Detweiler and Riedesel, 1993).

The shift in acid-base balance was also linked to the $\mathrm{BW}$ of the calf at birth, with lower values of blood $\mathrm{pH}$, $\mathrm{HCO}_{3}{ }^{-}$, and $\mathrm{BE}$ in calves with higher $\mathrm{BW}$ compared with newborns with a lower BW at birth, whereas $\mathrm{TCO}_{2}$ and L-lactate concentration increased with increased calf BW at birth (Table 2). Our data suggest that calves with a higher BW at birth are more exposed to acidosis than those with a lower BW at birth.

In modern dairy farming systems, the cow and the calf are usually separated after calving, which has implications for production efficiency and health (Nielsen, 2009). However, as the dam usually licks the calf within 
90 min after calving, in some dairies the cow and the calf are kept together for the first hour after birth because this process has a role in health and adaptation of the calf to extrauterine life. In the present study, rectal temperature was highly affected by the duration of maternal grooming, with higher values in those calves that were licked by the dam for a longer time (Table 2 ), suggesting that early parent-offspring interaction has benefits in terms of preventing newborns from hypothermia. Because newborn calves are covered by amniotic fluid, which decreases their body temperature due to evaporation, maternal grooming during the early hours of life and removing the fluid are particularly important at low ambient temperatures. However, we found no interaction between season and the duration of maternal licking.

When focusing on respiratory parameters, the values of $\mathrm{pO}_{2}$ increased, whereas those of $\mathrm{pCO}_{2}$ decreased with a longer duration of maternal grooming, suggesting that intensive mother-offspring contact may moderate neonatal hypoxia and the respiratory component of acidosis (Table 2). The severity of postnatal acidosis was also moderated by maternal grooming, as reflected by the increased values of blood $\mathrm{pH}, \mathrm{BE}$, and $\mathrm{HCO}_{3}^{-}$and decreased values of anion gap and L-lactate concentrations with a longer duration of licking the calf. On the one hand, calves receiving less maternal grooming within the first hour of life might became acidotic due to increased myofibrillar activity. On the other hand, tactile stimulation from the dam might have reduced the degree of respiratory acidosis by supporting respiration in calves receiving more intensive maternal contact.

Earlier studies did not investigate the direct association between neonatal acid-base status and cow-calf interaction; however, the onset and quality of maternal care have been stressed as being main motivators of expressing neonatal behaviors in ruminants (Alexander and Williams, 1964; Dwyer, 2008) and have been found to be crucial for the survival of newborn calves as well (von Keyserlingk and Weary, 2007). Although the lack of sufficient scientific data prevents us from providing an in-depth explanation for our results, it seems that the duration of licking the calf is a prominent factor in the thermal and metabolic adaptation of newborn calves to extrauterine life. Early removal of the calf (before standing) has been recommended to reduce postnatal morbidity and mortality in large dairies (McGuirk and Collins, 2004); however, based on our results, the positive effect of parent-offspring interaction should be considered in parturition management on dairy farms, especially where maternity facilities support calf health; that is, if calvings take place in individual maternity pens (Curtis et al., 1988; Mee, 2008).

\section{CONCLUSIONS}

Our results demonstrate that several factors have a significant effect on venous blood gas parameters of newborn calves within the first $24 \mathrm{~h}$ of life. In addition to the time of sampling relative to birth, season should be considered when assessing blood gas parameters in dairy calves. The severity of postnatal acidosis was affected by the duration of the delivery process and maternal grooming, both of which should be considered to have both animal welfare and technological implications. The role of physiological factors in the seemingly higher vitality of newborn calves in winter should be clarified in the future as it may have clinical and welfare implications as well.

\section{ACKNOWLEDGMENTS}

The authors thank Ferenc Bodó, farm owner, and Ágoston Bodó, farm manager, for supporting the study, and the farm staff of Prograg Agrárcentrum Ltd. at Ráckeresztúr, Lászlópuszta for taking care of the animals during the experimental period. Levente Kovács was partly supported by the following grants: János Bolyai Research Scholarship of the Hungarian Academy of Sciences (Budapest, Hungary); OTKA Research Scholarship of the National Research, Development and Innovation Office (Budapest, Hungary; PD123456); NTP-NFTÖ-16-0225 project by the Human Capacities Grant Management Office and the Hungarian Ministry of Human Capacities (Budapest, Hungary); and Research Center of Excellence (1476-4/2016/FEKUT project, Budapest, Hungary). Our work was supported by the Hungarian Academy of Sciences, Budapest, Hungary (2013 TKI 747).

\section{REFERENCES}

Alexander, G., and D. Williams. 1964. Maternal facilitation of sucking drive in newborn lambs. Science 146:665-666.

Azzam, S. M., J. E. Kinder, M. K. Nielsen, L. A. Werth, K. E. Gregory, L. V. Cundiff, and R. M. Koch. 1993. Environmental effects on neonatal mortality of beef calves. J. Anim. Sci. 71:282-290.

Barrier, A. C., M. J. Haskell, S. Birch, A. Bagnall, D. J. Bell, J. Dickinson, A. I. Macrae, and C. M. Dwyer. 2013. The impact of dystocia on dairy calf health, welfare, performance and survival. Vet. J. 195:86-90.

Barrier, A. C., E. Ruelle, M. J. Haskell, and C. M. Dwyer. 2012. Effect of a difficult calving on the vigour of the calf, the onset of maternal behaviour, and some behavioural indicators of pain in the dam. Prev. Vet. Med. 103:248-256.

Bellows, R. A., and M. A. Lammoglia. 2000. Effects of severity of dystocia on cold tolerance and serum concentrations of glucose and cortisol in neonatal beef calves. Theriogenology 53:803-813. 
Bleul, U. 2009. Respiratory distress syndrome in calves. Vet. Clin. North Am. Food Anim. Pract. 25:179-193.

Bleul, U., and E. Götz. 2013. The effect of lactic acidosis on the generation and compensation of mixed respiratory-metabolic acidosis in neonatal calves. Vet. Rec. 172:528.

Bleul, U., B. Lejeune, S. Schwantag, and W. Kähn. 2007. Ultrasonic transit-time measurement of blood flow in the umbilical arteries and veins in the bovine fetus during stage II of labor. Theriogenology 67:1123-1133.

Bleul, U., S. Schwantag, and W. Kahn. 2008. Blood gas analysis of bovine fetal capillary blood during stage II labor. Theriogenology 69:245-251.

Constable, P. D. 2014. Acid-base assessment: When and how to apply the Henderson-Hasselbalch equation and strong ion difference theory. Vet. Clin. North Am. Food Anim. Pract. 30:295-316.

Curtis, C. R., H. N. Erb, and M. E. White. 1988. Descriptive epidemiology of calfhood morbidity and mortality in New York Holstein herds. Prev. Vet. Med. 5:293-307.

Detweiler, D. K., and D. H. Riedesel. 1993. Regional and fetal circulations. Page 227 in Duke's Physiology of Domestic Animals. M. J. Swenson, and W. O. Reece, ed. Cornell University Press, Ithaca, NY.

Dwyer, C. M. 2008. Individual variation in the expression of maternal behavior: A review of the neuroendocrine mechanisms in the sheep. J. Neuroendocrinol. 20:526-534.

Guyton, A. C., and J. E. Hall. 2006. Regulation of respiration. Pages 516-523 in Medical Physiology. A. C. Guyton, and J. E. Hall, ed. Elsevier Saunders, Philadelphia, PA.

Hady, P. J., J. J. Domecq, and J. B. Kaneene. 1994. Frequency and precision of body condition scoring in dairy cattle. J. Dairy Sci. $77: 1543-1547$.

Harvey, J. W. 1997. The erythrocyte: Physiology, metabolism, and biochemical disorders. Pages 157-203 in Clinical Biochemistry of Domestic Animals. J. J. Kaneko, J. W. Harvey, and M. L. Bruss, ed. Academic Press, San Diego, CA.

Held, T., U. J. E. Eigenmann, and E. Grunert. 1985. Blutgasanalytische Untersuchungsbefunde bei bovinen Feten im Aufweitungsstadium der Geburt. Mh. Vet. Med. 40:405-409.

Herfen, K., and H. Bostedt. 1999. Correlation between clinical and laboratory diagnostic evaluation of the vitality of newborn calves under particular consideration of length and type of parturition. Wien. Tierarztl. Monatsschr. 86:255-261.

Homerosky, E. R., N. A. Caulkett, E. Timsit, E. A. Pajor, J. P. Kastelic, and M. C. Windeyer. 2017. Clinical indicators of blood gas disturbances, elevated L-lactate concentration and other abnormal blood parameters in newborn beef calves. Vet. J. 219:49-57.

Jensen, M. B. 2012. Behaviour around the time of calving in dairy cows. Appl. Anim. Behav. Sci. 139:195-202.

Kovács, L., F. L. Kézér, F. Ruff, and O. Szenci. 2017. Rumination time and reticuloruminal temperature as possible predictors of dystocia in dairy cows. J. Dairy Sci. 100:1568-1579.

Kovács, L., F. L. Kézér, and O. Szenci. 2016. Parturition progress, outcomes of calving and postpartum health of dairy cows underwent assisted and spontaneous calvings. J. Dairy Sci. 99:7568-7573.

Kurz, M. M., and L. B. Willett. 1991. Physiology and management; carbohydrate, enzyme, and hematology dynamics in newborn calves. J. Dairy Sci. 74:2109-2118.

Lombard, J. E., F. B. Garry, S. M. Tomlinson, and L. P. Garber. 2007. Impacts of dystocia on health and survival of dairy calves. J. Dairy Sci. 90:1751-1760.

Lorenz, I., B. Earley, J. Gilmore, I. Hogan, E. Kennedy, and S. J. More. 2011. Calf health from birth to weaning. I. General aspects of disease prevention. Ir. Vet. J. 64:10.

Maurer-Schweizer, H., U. Wilhelm, and K. Walser. 1977. Blutgase und Säure-Basen-Haushalt bei Lebensfrischen Kälbern in der ersten 24 Lebensstunden. Berl. Munch. Tierarztl. Wochenschr. 90:192-196.
McGuirk, S. M., and M. Collins. 2004. Managing the production, storage, and delivery of colostrum. Vet. Clin. North Am. Food Anim. Pract. 20:593-603.

Mee, J. F. 2008. Newborn dairy calf management. Vet. Clin. North Am. Food Anim. Pract. 24:1-17.

Mee, J. F., D. P. Berry, and A. R. Cromie. 2011. Risk factors for calving assistance and dystocia in pasture-based Holstein-Friesian heifers and cows in Ireland. Vet. J. 187:189-194.

Miedema, H. M., M. S. Cockram, C. M. Dwyer, and A. I. Macrae. 2011. Behavioural predictors of the start of normal and dystocic calving in dairy cows and heifers. Appl. Anim. Behav. Sci. 131:14-19.

Mülling, M. 1977. Asphyxie des neugeborenen Kalbes. Prakt. Tierarzt $58: 78-80$

Murray, C. F., and K. E. Leslie. 2013. Newborn calf vitality: Risk factors, characteristics, assessment, resulting outcomes and strategies for improvement. Vet. J. 198:322-328.

Murray, C. F., D. M. Veira, L. A. Nadalin, D. M. Haines, M. L. Jackson, D. L. Pearl, and K. E. Leslie. 2015. The effect of dystocia on physiological and behavioral characteristics related to vitality and passive transfer of immunoglobulins in newborn Holstein calves. Can. J. Vet. Res. 79:109-119.

Nielsen, S. S. 2009. Use of diagnostics for risk-based control of paratuberculosis in dairy herds. In Pract. 31:150-154.

R Core Team. 2013. R: A language and environment for statistical computing. R Foundation for Statistical Computing, Vienna, Austria. http://www.R-project.org/.

Rice, L. E. 1994. Dystocia-related risk factors. Vet. Clin. North Am. Food Anim. Pract. 10:53-68.

Schuijt, G. 1990. Iatrogenic fractures of ribs and vertebrae during delivery in perinatally dying calves: 235 cases (1978-1988). J. Am. Vet. Med. Assoc. 197:1196-1202.

Schuijt, G., and M. A. M. Taverne. 1994. The interval between birth and sternal recumbency as an objective measure of the vitality of newborn calves. Vet. Rec. 135:111-115.

Szenci, O. 1982. Correlations between muscle tone and acid-base balance in newborn calves: Experimental substantiation of a simple new score system proposed for neonatal status diagnosis. Acta Vet. Acad. Sci. Hung. 30:79-84.

Szenci, O. 1983. Effects of type and intensity of assistance on acid-base balance of newborn calves. Acta Vet. Hung. 31:73-79.

Szenci, O. 1985. Role of acid-base disturbances in perinatal mortality of calves (A summary of thesis). Acta Vet. Hung. 33:205-220.

Szenci, O. 2003. Role of acid-base disturbances in perinatal mortality of calves. Vet. Bull. 73:7R-14R. (review)

Szenci, O., B. P. Chew, A. C. Bajcsy, P. Szabo, and E. Brydl. 1994. Total and ionized calcium in parturient dairy cows and their calves. J. Dairy Sci. 77:1100-1105.

Szenci, O., M. A. M. Taverne, S. Bakonyi, and A. Erdődi. 1988. Comparison between pre- and postnatal acid-base status of calves and their perinatal mortality. Vet. Q. 10:140-144.

Vannucchi, C. I., J. A. Rodrigues, L. C. G. Silva, C. F. Lúcio, and G. A. L. Veiga. 2015. Effect of dystocia and treatment with oxytocin on neonatal calf vitality and acid-base, electrolyte and haematological status. Vet. J. 203:228-232.

Varga, J., L. Mester, L. Börzsönyi, P. Lekeux, and O. Szenci. 2001. Improved pulmonary adaptation in newborn calves with postnatal acidosis. Vet. J. 162:226-232.

Vermorel, M., C. Dardillat, J. Vernet, Non Renseigné, and C. Demigne. 1983. Energy metabolism and thermoregulation in the newborn calf. Annales de Recherches Vétérinaires, INRA Editions, 14:382-389. https://hal.archives-ouvertes.fr/hal-00901438.

von Keyserlingk, M. A. G., and D. M. Weary. 2007. Maternal behavior in cattle. Horm. Behav. 52:106-113. 